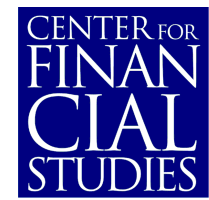

No. $2004 / 03$

Innovation and Market Concentration with Asymmetric Firms

Marc Escrihuela-Villar 


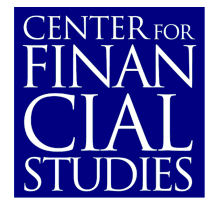

\section{Center for Financial Studies}

The Center for Financial Studies is a nonprofit research organization, supported by an association of more than 120 banks, insurance companies, industrial corporations and public institutions. Established in 1968 and closely affiliated with the University of Frankfurt, it provides a strong link between the financial community and academia.

The CFS Working Paper Series presents the result of scientific research on selected topics in the field of money, banking and finance. The authors were either participants in the Center's Research Fellow Program or members of one of the Center's Research Projects.

If you would like to know more about the Center for Financial Studies, please let us know of your interest.

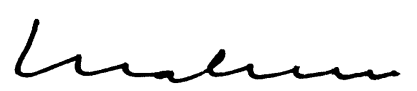

Prof. Dr. Jan Pieter Krahnen

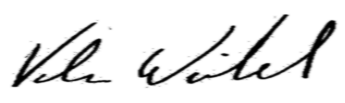

Prof. Volker Wieland, Ph.D. 


\title{
Innovation and Market Concentration with Asymmetric Firms ${ }^{1}$
}

\author{
Marc Escrihuela-Villar ${ }^{2}$
}

February, 2004

\begin{abstract}
:
This paper considers a theoretical model of $n$ asymmetric firms that reduce their initial unit costs by spending on R\&D activities. In accordance with Schumpeterian hypotheses we obtain that more efficient (bigger) firms spend more in R\&D and this leads to a more concentrated market structure. We also find a positive relationship between innovation and market concentration. This calls for a corrective tax on $R \& D$ activities to curtail strategic incentives to over-invest in $R \& D$ trying to achieve a higher market share.
\end{abstract}

JEL Classification: L11, L52, O31

Keywords: R\&D; Asymmetries; Market Concentration; Optimal Industrial Policies

\footnotetext{
${ }^{1}$ I would like to thank my advisor Ramon Faulí Oller for his advice and encouragement. Financial support by The Department of Economics of the University of Alicante and the Center for Financial Studies of Frankfurt is gratefully acknowledged. All errors are mine.

${ }^{2}$ Mailing address: Department of Economic Analysis, Campus San Vicente del Raspeig E-03080, University of Alicante, E-mail: marc@merlin.fae.ua.es

Center for Financial Studies (CFS), Taunusanlage 6, 60329 Frankfurt am Main, Germany,

E-mail: escrihuela-villar@ifk-cfs.de
} 


\section{Introduction}

The advantages for innovation of a firm being large were firstly pointed out by Schumpeter in his Capitalism, Socialism and Democracy (1942). He argued that there were innovation "capability advantages" of large firm size stemming from economies of scale in research and development (R\&D) and management, greater capabilities for risk spreading, finance, etc. In summary, large firms have a level of production, productive capacity, marketing arrangements, and finance that enables them quickly to exploit a new technology at relatively large scale. However, the argument that large firms can be more efficient in R\&D has been countered by arguments like that the bureaucratic control structure of large firms may partially or even fully offset these latent advantages, or even by the fact that weak competition may reduce the spur to innovation in large firms.

Despite substantial interest in the question little direct evidence on R\&D and market structure has appeared in the literature. Simultaneous influences between R\&D and concentration have been suggested and tested (see for example Connolly and Hirschey (1984) or Nelson and Winter (1982)). However, the literature on innovation and market structure has never reached a definitive conclusion on the relationship between firm size and investment in R\&D activities. Neither empirical observations nor theoretical models come to any clear conclusions on this subject.

In this paper, I address the important question of the relationship between innovation ${ }^{1}$ and market structure and how initial production costs affect the incentives to innovate.

On the one hand, it is also a common feature in the real world that firms differ, and this asymmetry might refer to size, cost structure or R\&D commitment. Although in the context of R\&D competition, it is important to understand how the outcome is influenced by the presence of asymmetries amongst firms, most of the literature on non-tournament models of innovation focuses on symmetric or identical firms. (see for example Spence (1984) or D'Aspremont and Jacquemin (1988)). In our model, asymmetry is presented by allowing firms to differ in their initial production costs.

\footnotetext{
${ }^{1}$ Innovations that reduce the cost of production of an existing good are called process innovations, while those that create new goods are called product innovations. We will focus on process innovations.
} 
On the other hand, while there are some theoretical models that have tried to capture the advantages of firms large size in R\&D in a duopoly (see for example Rosen (1991), Barros and Nilssen (1999), Poyago-Theotoky (1996) or Xiangkang and Zuscovitch (1998)), to the best of our knowledge, there has been no attempt to extend the model to the more general case of the oligopoly of $n$ firms $^{2}$.

Therefore, the aim of the paper is the following: in an asymmetric model of $n$ firms performing cost-reducing $\mathrm{R} \& \mathrm{D}$ activities, we analyze the incentives of the firms to innovate depending on their initial degree of efficiency. We also check how the implementation of $\mathrm{R} \& \mathrm{D}$ activities affects market concentration. $\mathrm{R} \& \mathrm{D}$ is assumed to be undertaken before the output is produced, with firms anticipating the effect of the $R \& D$ on the resolution of their market shares. I obtain that efficient firms spend more in $R \& D$ than inefficient firms, which means that larger firms, in terms of market share, invest more than smaller firms. Furthermore, they over-invest in $R \& D$ in order to increase their market share. This leads market concentration to increase confirming the Schumpeterian positive relationship between innovation and concentration.

As it was stressed, the strategic game played by firms leads to overuse $R \& D$ in absence of government policy. As national governments in a number of countries subsidize R\&D of firms, in our model, industrial policy is also discussed ${ }^{3}$. Two different measures are analyzed: production and $\mathrm{R} \& \mathrm{D}$ taxes (or subsidies). The motivation for the government policy in the paper is to tax R\&D efforts to curtail the strategic incentives of firms to over-invest in $R \& D$ to achieve a higher market share. The Optimal Industrial Policy also prescribes a production subsidy to compensate possible output decreases due to the R\&D tax. What is obtained is that the Optimal Industrial Policy decreases market concentration, as it is corrective to the increase in the initial production cost gap among firms provoked by the implementation of R\&D activities.

I also introduce a firm-specific industrial policy, which is different R\&D taxes among firms. The intuition behind it is that the support of R\&D activities may be, firm-specific or even project-specific. We obtain that firms are also generally taxed to reduce their in-

\footnotetext{
${ }^{2}$ Belleflame (2001) is an exception. However, his model differs from mine at least in two aspects. First, in his work firms are $e x$-ante identical and second, firms can also perform R\&D to differentiate the product.

${ }^{3}$ It has also been discussed in a few papers of international $R \& D$ competition, see for example Spencer and Brander (1983) or Miyagiwa and Ohno (1997).
} 
vestment in $R \& D$. However, the firm-specific policy prescribes that more quantity-efficient firms should be taxed at a lower rate, basically due to the fact that in the welfare maximization, the specific tax is used to divert production to the more efficient firms. Thus, by its nature, this firm-specific industrial policy causes an increase in market concentration.

In section 2 we present the model. In section 3 we analyze the relationship between innovation and concentration. In section 4 the optimal industrial policy is characterized. Section 5 concludes. All proofs are relegated to the appendix. 


\section{The Model}

We consider a market whose demand is given by a linear inverse demand function,

$$
P=a-Q
$$

Where $P$ is the price and $Q$ is total quantity supplied in the market. There are $n$ firms competing in quantities and selling a homogeneous good ${ }^{4}$, with $Q=\sum_{i=1}^{n} q_{i}$. The unit production cost depends on the R\&D activity performed by the firm in such a way that the R\&D outcome reduces the constant marginal cost of producing the final good. In particular, the unit production cost of firm $i$ is given by:

$$
d_{i}=c_{i}-x_{i}
$$

Where $c_{i}<a$ is the initial level of unit production cost of firm $i$, and $x_{i}$ is the level of firm $i \mathrm{R} \& \mathrm{D}$ investment, where $i=1, \ldots, n$. That is, as indicated by the subscripts, we do not restrict firms to be equal.

The R\&D costs are given by $\gamma x_{i}^{2}$ with $\gamma>0$. We assume $\gamma$ to be equal across firms. This is done for convenience as my interest lies in how asymmetries in costs functions, and therefore in firms' size in terms of market share, affect industrial policy and market structure. Therefore, firm $i$ profit function is:

$$
\Pi_{i}\left(q_{i}, d_{i}\right)=\left(P-d_{i}\right) q_{i}-\gamma\left(c_{i}-d_{i}\right)^{2}
$$

We assume in our model that R\&D is strategic and it involves a two-step game. The corresponding nonstrategic model would be one in which R\&D would be used only to minimize costs, and the equilibrium would be the standard cost-minimization Cournot equilibrium that would naturally arise if $\mathrm{R} \& \mathrm{D}$ and output were simultaneously determined.

\footnotetext{
${ }^{4}$ The assumption of a homogeneous good leads naturally to Cournot competition. Under Bertrand competition, no asymmetry can survive with a homogeneous good.
} 
In our model, firms simultaneously choose R\&D levels, these R\&D levels are made known to each other, and then output levels are also simultaneously determined. In the first stage, firms choose R\&D levels, and in the second stage, output levels. I look for the subgame perfect Nash equilibrium of this two stage game.

The quantities produced by each firm as a function of the vector $d=\left(d_{1}, \ldots, d_{n}\right)$, total output and price respectively in the second-stage equilibrium are:

$$
\begin{gathered}
q_{i}(d)=\frac{a-(n+1) d_{i}+\sum_{i=1}^{n} d_{i}}{n+1} \quad i=1, \ldots, n ; \\
\sum_{i=1}^{n} q_{i} \equiv Q=\frac{n a-\sum_{i=1}^{n} d_{i}}{n+1} \\
P=\frac{a+\sum_{i=1}^{n} d_{i}}{n+1}
\end{gathered}
$$

Then, from (4) and (6) respectively we obtain the effect of changes in marginal costs in the standard linear Cournot setting, that is:

$$
\frac{\partial q_{i}}{\partial d_{i}}=-\frac{n}{n+1} \quad \frac{\partial P}{\partial d_{i}}=\frac{1}{n+1} \quad \frac{\partial\left(\frac{q_{i}}{Q}\right)}{\partial d_{i}}<0
$$

To obtain the equilibrium in the first stage we make use of a technique developed in Saracho (2002) to deal with asymmetric situations. Although, in fact, firms choose the level of R\&D $\left(x_{i}\right)$, for computational reasons it will be more convenient to think that they choose the level of its marginal cost in the production stage $\left(d_{i}\right)$. (2) relates directly both variables. We assume also $\gamma \geq 1$, and therefore the convexity property required with respect to $x_{i}$ to ensure that second-order condition of firm $i^{\prime}$ s maximization problem is satisfied. Firm $i$ looks its final unit cost of production $\left(d_{i}\right)$ that maximizes its profits. The first order conditions are:

$$
\frac{\partial \prod_{i}\left(q_{i}, d_{i}\right)}{\partial d_{i}}=\left(P-d_{i}\right) \frac{\partial q_{i}}{\partial d_{i}}+\left(\frac{\partial P}{\partial d_{i}}-1\right) q_{i}+2 \gamma\left(c_{i}-d_{i}\right)=0 \quad i=1, \ldots, n
$$


We introduce (4), (5), (6) and (7) in (8) and simplifying we obtain that the first order condition for firm $i$ becomes:

$$
\frac{\partial \Pi_{i}\left(q_{i}, d_{i}\right)}{\partial d_{i}}=-2 n a-2 n \sum_{i=1}^{n} d_{i}+\left(2 n(n+1)-2 \gamma(n+1)^{2}\right) d_{i}+2 \gamma(n+1)^{2} c_{i}=0
$$

We proceed now adding all $n$ first order conditions, leading us to the following expression:

$$
-2 n^{2} a-2 n^{2} \sum_{i=1}^{n} d_{i}+\left(2 n(n+1)-2 \gamma(n+1)^{2}\right) \sum_{i=1}^{n} d_{i}+2 \gamma(n+1)^{2} \sum_{i=1}^{n} c_{i}=0
$$

Then,

$$
\sum_{i=1}^{n} d_{i}=\frac{-n^{2} a+\gamma(n+1)^{2} \sum_{i=1}^{n} c_{i}}{\gamma(n+1)^{2}-n}
$$

Thus, defining $c=\sum_{i=1}^{n} c_{i}$, if we replace (11) in (9) we obtain $d_{i}$.

$$
d_{i}=\frac{a n^{2}-\left(a+c+c_{i}\right) \gamma n(1+n)+c_{i} \gamma^{2}(1+n)^{2}}{(\gamma+(-1+\gamma) n)\left(-n+\gamma(1+n)^{2}\right)}
$$

Using (11) and (12) in (4) we can obtain the level of production ${ }^{5}$. Taking into account that $x_{i}=c_{i}-d_{i}$, from (12) we also obtain the optimal level of R\&D for firm $i^{6}$. They are respectively:

\footnotetext{
${ }^{5}$ It is implicitly assumed that firms are not too asymmetric in terms of their initial costs in such a way that in equilibrium we have $q_{i}>0 \forall i=1, \ldots, n$. This is implied by the following condition : $c_{i}<\frac{\left.\gamma \sum_{j \neq i}^{n} c_{j}(1+n)+a(\gamma+(-1+\gamma) n)\right)}{n(-1+\gamma(1+n))} \quad \forall i=1, \ldots, n$

Observe that this implies that in equilibrium all firms obtain positive profits and perform a positive amount of R\&D. Furthermore, it also implies that in equilibrium $x_{i} \leq c_{i}$.

${ }^{6}$ High levels of R\&D characterize this equilibrium for the output levels chosen. That is, the strategic behavior may induce firms to use more R\&D than required to minimize the cost of the output produced (see Brander and Spencer (1983)).
} 


$$
\begin{gathered}
q_{i}=\frac{\gamma(1+n)\left(c \gamma(1+n)+a(\gamma+(-1+\gamma) n)-c_{i}\left(-n+\gamma(1+n)^{2}\right)\right)}{(\gamma+(-1+\gamma) n)\left(-n+\gamma(1+n)^{2}\right)} \quad i=1, \ldots, n, \\
x_{i}=\frac{n\left(n c_{i}-\gamma\left((1+n)^{2} c_{i}-c\right)+a(\gamma+(-1+\gamma) n)\right)}{(\gamma+(-1+\gamma) n)\left(-n+\gamma(1+n)^{2}\right)} \quad i=1, \ldots, n,
\end{gathered}
$$

Whereas total output produced by firms in equilibrium is ${ }^{7}$ :

$$
Q=\frac{(1+n)(\gamma(a n-c))}{-n+\gamma(1+n)^{2}}
$$

\section{The R\&D Competition and market concentration}

From the previous equations we obtain that since $R \& D$ reduces constant marginal cost of producing, an equal R\&D outcome is proportionally more effective for a low-cost firm, as the cost reduction is applied to a greater amount of production. This leads us to the following result:

Proposition 1 The effects on outputs and RED investments of changes in parameters are:

$$
\frac{\partial x_{i}}{\partial \gamma}<0 ; \quad \frac{\partial x_{i}}{\partial c i}<0 ; \quad \frac{\partial q_{i}}{\partial \gamma}<0 ; \quad i=1, \ldots, n
$$

Thus, the initial cost gap among firms is broadened by the performance of $\mathrm{R} \& \mathrm{D}$ activities. This shows that ex-ante asymmetries in production costs result in a higher incentive to invest in $R \& D$ by a lower cost firm, and also shows that R\&D activities leads to an increase in production costs asymmetries. That means that low cost firms increase

\footnotetext{
${ }^{7}$ Observe that $Q>0$ is always satisfied as $c_{i}<a \Longrightarrow c<a n$.
} 
their lead over high-cost firms. R\&D activities can then be viewed as an instrument to leverage market power. This result has been already obtained for the duopoly case (see for example Barros and Nilssen (1999), Poyago-Theotoky (1996) or Rosen (1991)), however we have extended it for the $n$ firms case.

On the one hand, we see that if R\&D becomes more expensive ( $\gamma$ increases), the direct effect is that firms invest less, in such a way that when $\gamma$ goes to infinite, firms do not invest at all $\left(x_{i}=0\right)$, and the model becomes the standard Nash-Cournot model without R\&D. At the same time, as introduced by Proposition 1, and in line with its intuition, the level of R\&D performed by a firm depends negatively on its initial per unit production $\operatorname{cost}\left(c_{i}\right)$.

On the other hand, there is an indirect effect, when R\&D becomes more expensive firms reduce their production given that they do less $R \& D$ and therefore they are less efficient.

As I mentioned, an important issue would be to consider the effect of R\&D investment on market performance. Together with firm size, the relationship between market structure and innovative behavior is of major concern for economists and policy makers. The interest derives from the Schumpeterian hypothesis that "large firms are more than proportionately more innovative than small firms" (see Kamien and Schwartz, (1991)). Schumpeter suggests a positive relationship between market concentration and innovative activity. The possibility available to the innovator to exert market power provides him with the incentives to undertake the required investment. However, the theoretical models that have been developed in order to analyze the different aspects of the relationship do not provide us with clear conclusions. In this sense, several arguments are exposed; On the one hand, a more concentrated market would allow firms to better capture consumer value than a less concentrated market providing incentives for early adoption (Saloner and Shepard, (1995)). On the other hand, the counterargument seems to centre on the fact that this higher concentration would however, undermine the pressures to adopt exerted by the existence of higher levels of competition. A key issue in the analysis of market structure is endogeneity: market structure may impact on R\&D decisions, but R\&D decisions will also influence subsequent market structure. In this sense, we will try to shed some light from a somewhat different perspective: in a scenario where asymmetric firms spend on R\&D activities, to which structure does the market evolve? 
In the United States, The Federal Trade Commission (FTC) uses the HirschmanHerfindahl Index:

$$
H H I=\sum_{i=1}^{n}\left(\frac{\text { firm sales }}{\text { total sales }} * 100\right)^{2}
$$

as an indicator of whether or not an industry is subject to monopoly power. An HHI under 1000 is considered as an indicator of healthy competition. An HHI increase of 100 or more is likely to trigger an investigation, and a HHI above 1800 could be considered as evidence of a monopoly. We analyze the effect of the $R \& D$ cost on the Herfindahl Index (HI):

$$
H I=\sum_{i=1}^{n}\left(\frac{\text { firm sales }}{\text { total sales }}\right)^{2}
$$

It is just in a different scale of that the HHI, then: $H H I=10.000 * H I$. In our model of heterogeneous costs, we obtain the following result:

Proposition 2 The HI is decreasing in $\gamma$.

What Proposition 2 tells us is that as R\&D becomes more expensive, the market becomes less concentrated. The intuition comes basically from the following:

$$
\frac{\partial x_{i}}{\partial \gamma \partial c_{i}}=\frac{n^{2}(1+n)\left(2 n+\gamma(1+n)^{2}(-2+\gamma(1+n))\right.}{(\gamma+(-1+\gamma) n)^{2}\left(n-\gamma(1+n)^{2}\right)^{2}}>0 .
$$

As we know from Remark 1, as $\gamma$ increases firms spend less in R\&D. However, from the last derivative we know that the rate at which firms decrease their $R \& D$ depends positively on their initial unit production cost $\left(c_{i}\right)$. Therefore, as $\gamma$ increases, the more inefficient is the firm, the smaller is its $R \& D$ reduction. We have then, that inefficient firms get their market share increased through a smaller R\&D cut. In Proposition 2, we find a positive relationship between innovative and concentrated markets which is clearly Schumpeterian ${ }^{8}$.

\footnotetext{
8 "Creative firms prosper and in contrast, firms that do not innovate, or that innovate in ways consumers do not value, are destroyed by their more creative competitors" (Schumpeter (1942)). He calls this process of economic selection, the culling on non-innovative firms, creative destruction.
} 
Remark 1 The HI is higher when firms can perform cost reducing REDD activities.

On balance, our model predicts that increased cost of $\mathrm{R} \& \mathrm{D}(\gamma)$, controlling for other factors, has a negative effect on market concentration consistent with the Schumpeterian hypothesis that less concentrated-less innovative and concentrated-innovative markets schemes can be observed.

We have seen which is the effect on market concentration of the strategic R\&D. In the following section we will see which is the optimal government intervention and its consequences on firms behavior and on market structure.

\section{The Optimal Industrial Policy}

Market failures can provide a rationale for government intervention to either support or curtail incentives to perform private R\&D. It is frequently found in the literature ${ }^{9}$ that firms may use excessive strategic $R \& D$ to restrict competition. In this case, the level of $\mathrm{R} \& \mathrm{D}$ performed is higher than the one that would minimize production costs if $\mathrm{R} \& \mathrm{D}$ and output were simultaneously determined. What we are interested to see in this subsection is what does this behavior call for regarding the industrial policy. In our model of domestic firms without international competition, the strategic motive of the government for intervention to diminish the rivalry of foreign firms is excluded ${ }^{10}$. To that extent, two different policies are considered. Basically we want to check wether the industrial policy should either subsidize or tax R\&D activities and production. Therefore, we introduce a tax (or subsidy) on R\&D by itself and a tax (or subsidy) on production ${ }^{11}$.

The introduction of these policies affect both the levels of R\&D committed by firms and the resolution of the output game given $R \& D$ levels. We allow for a tax on each firm per unit of its R\&D investment. Denote this tax rate by $\sigma$. We also allow for a production

\footnotetext{
${ }^{9}$ See for example Brander and Spencer (1983) and Spencer and Brander (1983).

${ }^{10}$ See for example Spencer and Brander (1983) or Barros and Nilssen (1999).

${ }^{11} \mathrm{An}$ Issue not raised here which would have a bearing on the question of a tax vs. a subsidy on $\mathrm{R} \& \mathrm{D}$ is uncertainty. Bagwell and Staiger (1994) concluded that optimal R\&D policy would require a precise assessment of the role that uncertainty plays in the $R \& D$ process. Moreover, $R \& D$ subsidy can play a positive strategic role.
} 
tax on each firm of $\alpha$ per unit of output produced. Thus, we are now interested in the following three-stage game: in stage 1 the government decides on the optimal vector $(\sigma, \alpha)$ of taxes, that is the simultaneous introduction of $\mathrm{R} \& \mathrm{D}$ and output taxes. In stage 2 firms decide their level of R\&D activities, thus determining their production costs for the subsequent output decision. Finally in stage 3 firms decide their output levels.

Now firm $i$ has a profit function given by:

$$
\Pi_{i}\left(q_{i}, x_{i}, \sigma, \alpha\right)=(P-\alpha) q_{i}-\left(c_{i}-x_{i}\right) q_{i}-\gamma x_{i}^{2}-\sigma x_{i}
$$

We seek the subgame-perfect Nash equilibrium of this game. The government maximizes social welfare, taking into account consumers' surplus, firms' profits and revenues from the taxes. Thus, the government maximizes ${ }^{12}$ :

$$
W=\Sigma_{i=1}^{n}\left(\Pi_{i}\left(q_{i}, x_{i}, \sigma, \alpha\right)+\sigma x_{i}+\alpha q_{i}\right)+\frac{1}{2} Q^{2}
$$

Thus, now the equilibrium quantity produced by firm $i$ that is the solution to the third-stage problem, and the level of R\&D implemented by each firm that is the solution to the second-stage problem, both depend on the magnitude of the taxes $(\sigma, \alpha)$ chosen. Thus, we proceed like in the previous section and we obtain that maximizing firms profits (17) with respect to $d_{i}$ and adding all first order conditions again, the equivalent for (11) is now:

$$
\sum_{i=1}^{n} d_{i}=\frac{2 \gamma c(1+n)^{2}+n(1+n)^{2} \sigma-2 n^{2}(a-\alpha)}{2 \gamma(n+1)^{2}-2 n}
$$

So it is straightforward to obtain the R\&D and output levels in equilibrium that depend on the vector of taxes $(\sigma, \alpha)$.

At the same time, substituting in (18) the values for $q_{i}$ and $x_{i}$ obtained and maximizing with respect to $\sigma$ and $\alpha$, we get the explicit forms for the optimal R\&D and output taxes that would be implemented by the government. This leads us to the following result ${ }^{13}$ :

\footnotetext{
${ }^{12}$ The absence of a distortionary cost of public funds is assumed.

${ }^{13}$ See the Appendix for the Second Order Conditions.
} 
Proposition 3 The optimal industrial policy calls for a production subsidy $(\alpha<0)$ and for a tax on the level of R\&D performed by firms $(\sigma>0)$. The equilibrium tax and the equilibrium subsidy are respectively:

$$
\begin{aligned}
\sigma^{*} & =\frac{2 \gamma(1+n)(-1+3 n)(a n-c)}{n\left(-1+3 n\left(-2-3 n+2 \gamma(1+n)^{2}\right)\right)} \\
\alpha^{*} & =\frac{2(c-a n)\left(n+3\left(n^{2}+\gamma(1+n)^{2}\right)\right)}{n\left(-1+3 n\left(-2-3 n+2 \gamma(1+n)^{2}\right)\right)}
\end{aligned}
$$

We can observe that the policy prescribes taxing the level of R\&D performed by the firms to curtail the strategic incentive to over-invest, while at the same time prescribes an output subsidy to stimulate production. Then, the effect (see Barros and Nilssen (1999)) of the profit-shifting motive that calls for a $R \& D$ subsidy in quantity competition is offset by the fact that firms spend too much in R\&D. Thus, the tax corrects the incentives to do R\&D beyond what cost minimization prescribes, meanwhile the output subsidy encourages firms' production.

Some comparative statics' about (20) and (21) can be obtained to clarify:

\section{Remark 2}

$$
\frac{\partial \sigma^{*}}{\partial \gamma}<0 ; \quad \frac{\partial \alpha^{*}}{\partial \gamma}>0
$$

The first derivative tells us that when the cost of R\&D increases, as the level implemented by firms is reduced (see Proposition 1), the optimal policy calls for a lower tax on the R\&D activities. At the same time the second derivative, following the intuition described above, claims that when the cost of R\&D increases, the optimal output subsidy is reduced. The reason is that the need to stimulate production to offset the effect of the R\&D tax on firms' production is lower when the tax is lower because the cost of R\&D increases.

Once the optimal industrial policy has been characterized, we are now ready to see the effect of both policy tools on market concentration. The consequences of the introduction 
of both policy instruments on firms' production and on firms' level of R\&D clarify matters. Defining $q_{i}\left(\sigma^{*}, \alpha^{*}\right)$ and $x_{i}\left(\sigma^{*}, \alpha^{*}\right)$ like the quantity produced and the level of R\&D implemented by each firm under the optimal industrial policy characterized by (20) and $(21)^{14}$. Using $q_{i}$ and $x_{i}$ from (13) and (14), and comparing, we obtain that:

$$
\begin{aligned}
& q_{i}\left(\sigma^{*}, \alpha^{*}\right)-q_{i}=\frac{\gamma(1+n)(a n-c)\left(1+3 n^{2}+6 \gamma(1+n)^{2}\right)}{\left(n\left(-n+\gamma(1+n)^{2}\right)\left(-1+3 n\left(-2-3 n+2 \gamma(1+n)^{2}\right)\right)\right.} \\
& x_{i}\left(\sigma^{*}, \alpha^{*}\right)-x_{i}=\frac{(c-a n)\left(-2 n^{2}(1+3 n)+\gamma(1+n)^{2}(-1+n(-4+3 n))\right)}{\left(n\left(-n+\gamma(1+n)^{2}\right)\left(-1+3 n\left(-2-3 n+2 \gamma(1+n)^{2}\right)\right)\right.}, \\
& \text { thus, }(\text { as } \gamma \geq 1 \text { and } c<\text { an }):
\end{aligned}
$$

$$
\begin{array}{ll}
q_{i}<q_{i}\left(\sigma^{*}, \alpha^{*}\right) & \forall i \in 1, \ldots, n \\
x_{i}>x_{i}\left(\sigma^{*}, \alpha^{*}\right) & \forall i \in 1, \ldots, n
\end{array}
$$

That is, the simultaneous output subsidy and R\&D tax expand firms' production. However it is important to remark that this is achieved reducing the level of R\&D performed by firms in equilibrium. Therefore, the effect of strategic R\&D to lower own marginal cost to get a higher market share is reduced by the tax but at the same time the potential reduction in output is compensated by the subsidy. The linearity of the model allows us to present an interesting lemma that introduces which is the effect of (20) and (21) on the market structure.

Lemma 4 The following holds:

$$
q_{i}\left(\sigma^{*}, \alpha^{*}\right)-q_{j}\left(\sigma^{*}, \alpha^{*}\right)=q_{i}-q_{j} \quad \forall i, j \in 1, \ldots, n
$$

This means that variations on firms' production due to the introduction of the optimal industrial policy formed by $(\sigma, \alpha)$ do not depend on the initial production cost of the firm. This leads us directly to the following result:

\footnotetext{
${ }^{14}$ See the Appendix for a proof that the equilibrium with the Optimal Industrial Policy is also interior.
} 
Proposition 5 The introduction of the optimal industrial policy characterized by (20) and (21) reduces the $H I$.

The market becomes less concentrated. Basically we have that with a subsidy on production and with a tax on the $\mathrm{R} \& \mathrm{D}$, the effect described in Proposition 2 of efficient firms achieving a higher market share via an over-investment in strategic $R \& D$ vanishes. This proposition implies that one of the consequences of the strategic R\&D performed by firms in an asymmetric market, that the industrial policy wants to mitigate, is the raise in market concentration.

A related question would be the relationship between both policy tools. In this sense, the following result shows how the prescribed production subsidy is influenced by the need to tax the over-investment in $\mathrm{R} \& \mathrm{D}$. We get the following:

Lemma 6 The optimal production subsidy that would be prescribed in absence of a RED tax is smaller than (21).

The intuition of the last result is clear. The presence of a $R \& D$ tax calls for a higher output subsidy given that the tax reduces the level of the R\&D performed by firms, and also has the effect of cutting firms production.

Another interesting issue would be then to analyze which is solely the effect of the tax on R\&D on the HI. In this sense, an interesting comparison would be to see Proposition 3 and 5 when there are no production subsidies. Assume $\alpha=0$. It is easy to see that now we have that the optimal tax on the level of $R \& D$ is:

$$
\sigma^{\prime}=\frac{2(a n-c)\left(-2 n^{2}+\gamma(1+n)^{2}(3 n-2)\right)}{n(1+n)^{2}\left(-2-5 n+6 \gamma(1+n)^{2}\right)}
$$

We obtain again that $\sigma^{\prime}>0{ }^{15}$. The absence of production subsidies does not change the policy prescription of taxing firms to reduce firms' incentives to over-invest in strategic

\footnotetext{
${ }^{15}$ As in Barros and Nilssen (1999) we find that when production subsidies are not implemented, the optimal industrial policy calls for a tax on the R\&D. Their tax however, is a firm-specific industrial policy in an open economy with foreign competition.
} 
R\&D. However, the homogeneity of the tax lead us to the following result, which is the equivalent to Proposition 6:

Proposition 7 The introduction of the optimal industrial policy characterized by (23) increases the HI.

From the last Proposition we see that with the introduction of an industrial policy where production is not subsidized, the market becomes more concentrated. Although the $R \& D$ tax reduces the level of $R \& D$ implemented by the firm, efficient firms achieve a higher market share because under this tax structure firms are equally penalized independently of their initial production costs. Therefore, with the introduction of (23), firms become more quantity asymmetric. This Proposition implies that it is precisely the introduction of the production subsidy $(\alpha)$ what reduces the concentration of the market.

\subsection{A Firm-specific industrial policy}

Our concern in this subsection is about one important aspect of $R \& D$ subsidies or taxes that distinguishes these policy instruments from other trade-policy instruments. While the former instruments tend to be industry-specific, the support (or taxation) of $\mathrm{R} \& \mathrm{D}$ activities can also be, by its nature, firm specific and even project specific.

Barros and Nilssen (1999) do comparative statics about the nature of a firm-specific industrial policy. Their model however, basically differs from ours as they do not specify a particular form for R\&D costs and therefore they can not explicitly solve the model. Furthermore they do not consider consumers' surplus in national welfare.

However, when R\&D activities are either taxed or subsidized differently among firms, the question that naturally arises is which firm should receive such support or be taxed. In our asymmetric model we face this question, asking whether firms should get their R\&D output taxed or not and which firms should pay the lowest tax or get the highest subsidy.

To that extent we consider the introduction of a firm specific R\&D tax (or subsidy) that we call $\sigma_{i}$. The timing of the game is the same three-stage situation described in the last subsection. Therefore the profits that firm $i$ would obtain are: 


$$
\Pi_{i}\left(q_{i}, x_{i}, \sigma_{i}\right)=q_{i}^{2}-\gamma x_{i}^{2}-\sigma_{i} x_{i}
$$

Output produced by firm $i$ that depend on $\sigma_{i}$ and total output produced by firms are easily obtained. We proceed again like in the previous subsection looking for the new production cost $\left(d_{i}\right)$ that maximizes firms profits ${ }^{16}$. They are the solution to the second stage problem:

$$
\begin{gathered}
q_{i}=\frac{\left.(1+n)\left(2 c \gamma^{2}(1+n)+2 a \gamma(\gamma+(-1+\gamma) n)-\left(-n+\gamma(1+n)^{2}\right)\left(2 c_{i} \gamma+\sigma_{i}\right)+\gamma(1+n) \Sigma_{i=1}^{n} \sigma_{i}\right)\right)}{2(\gamma+(-1+\gamma) n)\left(-n+\gamma(1+n)^{2}\right)} \\
Q=\frac{(1+n)\left(-2 c \gamma+2 a n \gamma-\sum_{i=1}^{n} \sigma_{i}\right)}{2\left(-n+\gamma(1+n)^{2}\right)}
\end{gathered}
$$

At the same time we know that each firm's first-order condition with respect to the level of its R\&D investment is:

$$
\frac{\partial \Pi_{i}\left(q_{i}, x_{i}, \sigma_{i}\right)}{\partial x_{i}}=2 q_{i} \frac{\partial q_{i}}{\partial x_{i}}-2 \gamma x_{i}-\sigma_{i}=0
$$

Whereas the government maximizes social welfare that is:

$$
W=\Sigma_{i=1}^{n}\left(\Pi_{i}\left(q_{i}, x_{i}, \sigma_{i}\right)\right)+\frac{1}{2} Q^{2}+\sigma_{i} x_{i}
$$

To have governments' preferred outcome, we proceed like in Barros and Nilssen (1999). To obtain the equilibrium, we proceed to the first stage, the government chooses an R\&D tax for each firm. The tax is obtained in the following way. It is assumed that the government is able to choose $\mathrm{R} \& \mathrm{D}$ activities for each firm, $x_{i}$, directly. Therefore, the optimal government choices solve the following condition:

$$
\frac{\partial W}{\partial x_{i}}=2\left[\sum_{j=1}^{n} q_{j} \frac{\partial q_{j}}{\partial x_{i}}\right]-2 \gamma x_{i}+\sum_{j=1}^{n} q_{j} \sum_{j=1}^{n} \frac{\partial \Sigma_{j=1}^{n} q_{i}}{\partial x_{i}}=0
$$

\footnotetext{
${ }^{16}$ In this subsection it is assumed that the government is only interested in the social optimality of R\&D. Therefore, only a firm-specific policy regarding the investments in innovation is considered.
} 
Therefore, the optimal firm-specific policy should make (29) and (27) hold. Since in our model $\frac{\partial q_{i}}{\partial x_{i}}=\frac{n}{n+1}$ and $\frac{\partial q_{i}}{\partial x_{j}}=-\frac{1}{n+1}$, we have that:

$$
\sigma_{i}=\frac{Q-2 q_{i}}{n+1}
$$

Where $q_{i}$ and $Q$ are "post-tax" quantities, respectively (25) and (26). Barros and Nilssen (1999) without considering consumers surplus in the social welfare obtain $\sigma_{i}=$ $\frac{2\left(Q-q_{i}\right)}{n+1}$. That is, they obtain that the industrial firm-specific policy prescribes always a tax for each firm. However, we obtain the specific form for the optimal industrial firmspecific tax (or subsidy). To that extent, we replace (25) and (26) in (30) and adding up to $n$. We obtain:

$$
\sum_{i=1}^{n} \sigma_{i}=\frac{2(a-c) \gamma(-2+n) n}{-2-n+2 \gamma(1+n)^{2}}
$$

Replacing (31) in (25) and (26), we are ready to obtain the explicit form for the firm-specific policy described in (30). It leads us to the following result:

Proposition 8 The optimal industrial firm-specific policy prescribes a tax on the R\&D when the firm does not have a market share larger than $\frac{1}{2}$. Otherwise, the policy prescribes a subsidy. The equilibrium tax (or subsidy) is:

$$
\sigma_{i}=\frac{\gamma\left(a(-2+n)(\gamma+(-1+\gamma) n)+c(n-3 \gamma(1+n))+2 c_{i}\left(-n+\gamma(1+n)^{2}\right)+\frac{(a-c)(-2+n) n(n-3 \gamma(1+n))}{-2-n+2 \gamma(1+n)^{2}}\right)}{(-1+\gamma)(1+n)\left(-n+\gamma(1+n)^{2}\right)}
$$

Last proposition specifies that a firm-specific policy also prescribes taxing firms to curtail the strategic incentive to over-invest in R\&D unless the firm is so efficient that the market is almost monopolized. In this case, the optimal policy calls for a subsidy to the $\mathrm{R} \& \mathrm{D}$ of this firm.

A related question is how firms are penalized by the tax because they are better positioned or not from the start. Looking at (32), we see that: 
Remark 3 Those firms that are more efficient are taxed less.

This remark implies that more efficient firms are penalized less than inefficient firms by the government because they are somehow more cost-effective in conducting $\mathrm{R} \& \mathrm{D}$ activities. More quantity-efficient firms should be taxed at a lower rate. This means that the tax is used to divert production to the more efficient firms.

A central question is, of course, how this firm specific policy affects market structure. As we can deduce from the last proposition, we obtain the following result:

Proposition 9 The introduction of the optimal firm-specific policy increases the HI.

We can see from the last proposition that the firm-specific policy described in Proposition 8 increases market concentration. It is clear form Remark 4 that through the policy described by the vector (32) ex-ante asymmetries in production costs are increased and then the structure of the market becomes more concentrated.

\section{Conclusions}

In this paper we have presented a simple model of $\mathrm{R} \& \mathrm{D}$ competition of $n$ firms placed asymmetrically at the start of the game. Firms compete to get a cost reduction. What it is obtained, in accordance with Schumpeterian hypotheses, is that if we consider large firms as those who have a larger initial market share, they spend more in $R \& D$ than small firms. Basically, this is true due to the fact that large firms use $R \& D$ activities to reduce competition achieving a higher market share. The more efficient is the firm from the start, as an equal $\mathrm{R} \& \mathrm{D}$ cost-reducing outcome is applied to a greater amount of production, the larger are the incentives to innovate. The conclusions are that the overinvestment in $\mathrm{R} \& \mathrm{D}$ beyond what cost minimization would prescribe leads to an increase in market concentration.

The main point is therefore, that the relationship between market concentration and innovation is positive and should be corrected by an optimal industrial policy. Within the limited context of the model presented in this paper, some implications on the design of a 
policy can be drawn, and this is that when $R \& D$ activities are used to reduce competition a corrective tax is needed. This corrective tax, together with a production subsidy reduces market concentration.

When the policy is firm-specific, the government taxes less the more efficient firms, basically because the policy is used as an instrument to divert production to the more efficient firms.

Several issues have been left for future research. First, it could be fruitful to apply to a more general framework, allowing firms to differ in their R\&D efficiency or to a more general demand and cost functions. Second, as we pointed out in the introduction, the relationship between firm size and investment in $R \& D$ activities is not clear in the literature. The present model considers firms' size in terms of market share, however, other different means to measure firms' size can also be used, considering for example firms with different fixed costs or facing asymmetric costs to entry the market. 


\section{Appendix}

Footnote 13: The Second Order Conditions for the government maximizing social welfare are hold as the Matrix:

$$
\left(\begin{array}{cc}
\frac{\partial^{2} W}{\partial^{2} \sigma} & \frac{\partial^{2} W}{\partial \sigma \partial \alpha} \\
\frac{\partial^{2} W}{\partial \alpha \partial \sigma} & \frac{\partial^{2} W}{\partial^{2} \alpha}
\end{array}\right)=\left(\begin{array}{cc}
\frac{-n(1+n)^{2}\left(-2-5 n+6 \gamma(1+n)^{2}\right)}{4\left(n-\gamma(1+n)^{2}\right)^{2}} & \frac{n\left(n+3 n^{2}-\gamma(1+n)^{2}(-1+4 n)\right)}{2\left(n-\gamma(1+n)^{2}\right)^{2}} \\
\frac{n\left(n+3 n^{2}-\gamma(1+n)^{2}(-1+4 n)\right)}{2\left(n-\gamma(1+n)^{2}\right)^{2}} & \frac{-\gamma n^{2}\left(-2+\gamma(1+n)^{2}\right)}{\left(n-\gamma(1+n)^{2}\right)^{2}}
\end{array}\right)
$$

is negative definite.

Footnote 14: The assumption taken in footnote 5 on production costs asymmetries is also enough to ensure that all firms produce under the optimal industrial policy $\left(q_{i}\left(\sigma^{*}, \alpha^{*}\right)>0 \forall i\right)$ and we are in an interior equilibrium. The condition required for $q_{i}\left(\sigma^{*}, \alpha^{*}\right)>0 \forall i$ is $c_{i} \leq c_{i}^{*}=\frac{6 a n(1+n)(-1+\gamma) n+\sum_{j \neq i}^{n} c_{j}\left(-1-3 n^{2}+6 \gamma(-1+n)(1+n)^{2}\right)}{1-n-3 n^{2}(1+3 n)+6 \gamma\left(1+n+n^{3}+n^{4}\right)}$. We assumed that $c_{i}<c_{i}^{1}=\frac{\left.\gamma \sum_{j \neq i}^{n} c_{j}(1+n)+a(\gamma+(-1+\gamma) n)\right)}{n(-1+\gamma(1+n))}$ and we have that $c_{i}^{1}<c_{i}^{*}$ if $a+\sum_{j \neq i}^{n} c_{j}<a n$, which is true if $c_{i}<a \forall i$.

Proof. Proposition 1: The level of R\&D implemented by firms in equilibrium is given by the expression:

$$
x_{i}\left(c_{i}, \gamma\right)=\frac{n\left(n c_{i}-\gamma\left((1+n)^{2} c_{i}-c\right)+a(\gamma+(-1+\gamma) n)\right)}{(\gamma+(-1+\gamma) n)\left(-n+\gamma(1+n)^{2}\right)}
$$

So we have:

$\frac{\partial x_{i}\left(c_{i}, \gamma\right)}{\partial \gamma}=\frac{n(1+n)\left(-a(1+n)(\gamma+(-1+\gamma) n)^{2}-c\left(\gamma^{2}+3 \gamma^{2} n+\left(-1+3 \gamma^{2}\right) n^{2}+\gamma^{2} n^{3}+c_{i}\left(n-\gamma(1+n)^{2}\right)^{2}\right)\right.}{(\gamma+(-1+\gamma) n)^{2}\left(n-\gamma(1+n)^{2}\right)^{2}}$ which is negative whenever the initial condition on $c_{i}$ is hold.

$$
\begin{aligned}
& \frac{\partial x_{i}\left(c_{i}, \gamma\right)}{\partial c i}=-\frac{n}{\gamma+(-1+\gamma) n}<0(\text { as } \gamma \geq 1) \\
& \frac{\partial q_{i}}{\partial \gamma}<0 \text { is implied by }(2),(4) \text { and } \frac{\partial x_{i}\left(c_{i}, \gamma\right)}{\partial \gamma}<0 .
\end{aligned}
$$

Proof. Proposition 2: The HI is given by the following expression:

$$
H I=\frac{-2 a c(\gamma+(-1+\gamma) n)^{2}+a^{2} n(\gamma+(-1+\gamma) n)^{2}+d\left(n-\gamma(1+n)^{2}\right)^{2}-c^{2} \gamma(1+n)(-2 n+\gamma(1+n)(2+n))}{(c-a n)^{2}(\gamma+(-1+\gamma) n)^{2}}
$$

where $d=\sum_{i=1}^{n} c_{i}^{2}$. Thus, $\frac{\partial H I}{\partial \gamma}=\frac{2 n(1+n)\left(c^{2}-d n\right)\left(-n+\gamma(1+n)^{2}\right)}{(c-a n)^{2}(\gamma+(-1+\gamma) n)^{3}}$. The sign of this derivative depends on $\left(c^{2}-d n\right)$. We have that this is negative when $\left(\sum_{i=1}^{n} c_{i}\right)^{2}<n \sum_{i=1}^{n} c_{i}^{2}$ which is true if $0<n \sum_{i=1}^{n} c_{i}^{2}-\left(n \frac{\sum_{i=1}^{n} c_{i}}{n}\right)^{2}$ that is when $0<n \sum_{i=1}^{n} c_{i}^{2}-n^{2} \bar{c}^{2}$. (Where $\bar{c}=\frac{\sum_{i=1}^{n} c_{i}}{n}$ is the average cost). So, $0<\frac{n}{n}\left(n \sum_{i=1}^{n} c_{i}^{2}-n^{2} \bar{c}^{2}\right)$ holds if $0<n^{2}\left(\frac{\sum_{i=1}^{n} c_{i}^{2}-n^{2} \bar{c}^{2}}{n}\right)$. On the other 
hand, we can develop $\sum_{i=1}^{n} \frac{\left(c_{i}-\bar{c}\right)^{2}}{n}$ which is the sample variance and therefore always positive, that is $\frac{\sum_{i=1}^{n}\left(c_{i}^{2}-2 \bar{c} c_{i}+\bar{c}^{2}\right)}{n}=\frac{\sum_{i=1}^{n} c_{i}^{2}-2 \bar{c} \sum_{i=1}^{n} c_{i}+n \bar{c}^{2}}{n}=\frac{\sum_{i=1}^{n} c_{i}^{2}-2 n \bar{c}^{2}+n \bar{c}^{2}}{n}=\frac{\sum_{i=1}^{n} c_{i}^{2}-n^{2} \bar{c}^{2}}{n}>$ 0 . So, the arithmetic mean of values $c_{1}, \ldots, c_{n}$ is lower than their quadratic mean. This holds when $c_{i} \geq 0 \forall i=1, \ldots, n$ and $\exists i, j$ such that $c_{i} \neq c_{j}$.

Proof. Proposition 3: We have that the taxes in equilibrium are respectively:

$$
\begin{aligned}
\sigma^{*} & =\frac{2 \gamma(1+n)(-1+3 n)(a n-c)}{n\left(-1+3 n\left(-2-3 n+2 \gamma(1+n)^{2}\right)\right)} \\
\alpha^{*} & =\frac{2(c-a n)\left(n+3\left(n^{2}+\gamma(1+n)^{2}\right)\right)}{n\left(-1+3 n\left(-2-3 n+2 \gamma(1+n)^{2}\right)\right)}
\end{aligned}
$$

The denominator of $\left(\sigma^{*}, \alpha^{*}\right)$ is positive if $\gamma>\frac{(1+3 n)^{2}}{6 n(1+n)^{2}}$, which is true as $\gamma \geq 1$. Then the sign of the taxes depends only on its numerator. We have that $c_{i}<a$, therefore $\sum_{i=1}^{n} c_{i}=c<$ an. So, $\sigma^{*}>0$ and $\alpha^{*}<0$.

Proof. Lemma 4: We have that $q_{i}(\sigma, \alpha)=\frac{a-\alpha-(n+1) d_{i}(\sigma, \alpha)+\sum_{i=1}^{n} d_{i}(\sigma, \alpha)}{n+1}$ where:

$$
\begin{gathered}
d_{i}(\sigma, \alpha)=-\frac{2 c_{i} \gamma(1+n)^{2}+(1+n)^{2} \sigma+2 n(\alpha-a)-\frac{n\left(2 c \gamma(1+n)^{2}+n\left(-2 a n+(1+n)^{2} t+2 n \alpha\right)\right.}{-n+\gamma(1+n)^{2}}}{2(1+n)(n-\gamma(1+n))} \\
\sum_{i=1}^{n} d_{i}(\sigma, \alpha)=\frac{2 c \gamma(1+n)^{2}+n(1+n) \sigma-2 n^{2}(a-\alpha)}{-2 n+2 \gamma(1+n)^{2}}
\end{gathered}
$$

and

$$
q_{i}=\frac{\gamma(1+n)\left(c \gamma(1+n)+a(\gamma+(-1+\gamma) n)-c_{i}\left(-n+\gamma(1+n)^{2}\right)\right)}{(\gamma+(-1+\gamma) n)\left(-n+\gamma(1+n)^{2}\right)}
$$

it is tedious but straightforward to check that $q_{i}(\sigma, \alpha)-q_{j}(\sigma, \alpha)=q_{i}-q_{j}$ holds.

Proof. Proposition 5: We have that $H I \equiv \sum_{i=1}^{n}\left(\frac{q_{i}}{Q}\right)^{2}$. Thus, using Lemma 4 we have that the introduction of the optimal industrial policy characterized by $\sigma^{*}$ and $\alpha^{*}$ means that the concentration index turns to $H I^{\prime}=\sum_{i=1}^{n}\left(\frac{q_{i}+\epsilon}{Q+n \epsilon}\right)^{2}$ where $\epsilon$ is the variation on firms production due to $\left(\sigma^{*} \alpha^{*}\right)$ and it is the same across all firms. Therefore, as $\sum_{i=1}^{n}\left(\frac{q_{i}+\epsilon}{Q+n \epsilon}\right)^{2}=$ $\frac{\sum_{i=1}^{n} q_{i}^{2}+n \epsilon^{2}+2 \epsilon \sum_{i=1}^{n} q_{i}}{(Q+n \epsilon)^{2}}$, if we compare both indexes we have: $H I-H I^{\prime}=\sum_{i=1}^{n}\left(\frac{q_{i}}{Q}\right)^{2}-$ $\frac{\sum_{i=1}^{n} q_{i}^{2}+n \epsilon^{2}+2 \epsilon \sum_{i=1}^{n} q_{i}}{(Q+n \epsilon)^{2}}>0 \Longleftrightarrow \frac{n^{2} \epsilon^{2} \sum_{i=1}^{n} q_{i}^{2}+2 Q n \epsilon \sum_{i=1}^{n} q_{i}^{2}}{Q^{2}(Q+n \epsilon)^{2}}>\frac{n \epsilon^{2}+2 \epsilon \sum_{i=1}^{n} q_{i}}{(Q+n \epsilon)^{2}}$. So $n^{2} \epsilon^{2} \sum_{i=1}^{n} q_{i}^{2}+$ $2 Q n \epsilon \sum_{i=1}^{n} q_{i}^{2}>Q^{2} n \epsilon^{2}+2 \epsilon Q^{2} \sum_{i=1}^{n} q_{i} \Longleftrightarrow \epsilon\left(n^{2} \epsilon \sum_{i=1}^{n} q_{i}^{2}+2 Q n \sum_{i=1}^{n} q_{i}^{2}\right)>\epsilon Q^{2}(n \epsilon+2 Q)$ given that $\epsilon>0$ (it is easy to see that $\left.q_{i}\left(\sigma^{*}, \alpha^{*}\right)>q_{i}\right)$ The last conditions turns to be 
$n \sum_{i=1}^{n} q_{i}^{2}(n \epsilon+2 Q)>Q^{2}(n \epsilon+2 Q)$. This is equivalent to $n \sum_{i=1}^{n} q_{i}^{2}>Q^{2}$ and therefore, to $\frac{\sum_{i=1}^{n} q_{i}}{n}<\sqrt[2]{\frac{\sum_{i=1}^{n} q_{i}^{2}}{n}}$. The latter inequality holds when $q_{i} \geq 0, \forall i=1, \ldots, n$ and $\exists i, j$ such that $q_{i} \neq q_{j}$.

Proof. Lemma 6: The optimal production subsidy it is obtained assuming $\sigma=0$. Then we obtain that:

$$
\alpha=\frac{(c-a n)\left(\gamma+n+2 \gamma n+(-1+\gamma) n^{2}\right)}{n^{2}\left(-2+\gamma(1+n)^{2}\right)}<0
$$

then we can check that the proposition holds by simply seeing $\alpha^{*}-\alpha<0$.

Proof. Proposition 7: We can see that when the industrial policy consists of assuming $\alpha=0$ and introducing $\sigma^{\prime}>0$. We can see that the equivalent for Lemma 4 also holds: $q_{i}\left(\sigma^{\prime}, 0\right)-q_{j}\left(\sigma^{\prime}, 0\right)=q_{i}-q_{j}$. Therefore, we can apply the reasoning of the Proof of Proposition 5 in the following way: now $\epsilon<0$, so $H I$ decreases whenever $H I \equiv \sum_{i=1}^{n}\left(\frac{q_{i}}{Q}\right)^{2}>\frac{1}{n}$, which again holds when $q_{i} \geq 0, \forall i=1, \ldots, n$ and $\exists i, j$ such that $q_{i} \neq q_{j}$.

Proof. Proposition 8: It is immediate to see that as we obtained:

$$
\sigma_{i}=\frac{Q-2 q_{i}}{n+1}
$$

so, $\sigma_{i}>0$ whenever $\frac{q_{i}}{Q}<\frac{1}{2}$

Proof. Proposition 9: The introduction of the firm-specific industrial policy is characterized by:

$$
\sigma_{i}=\frac{\gamma\left(a(-2+n)(\gamma+(-1+\gamma) n)+c(n-3 \gamma(1+n))+2 c_{i}\left(-n+\gamma(1+n)^{2}\right)+\frac{(a-c)(-2+n) n(n-3 \gamma(1+n))}{-2-n+2 \gamma(1+n)^{2}}\right)}{(-1+\gamma)(1+n)\left(-n+\gamma(1+n)^{2}\right)}
$$

So if we compare the $H I$ before and after the introduction of $\delta_{i}$ we can see that they are respectively $H I \equiv \sum_{i=1}^{n}\left(\frac{q_{i}}{Q}\right)^{2}$ and $H I^{\prime}=\sum_{i=1}^{n}\left(\frac{q_{i}+\sum_{i=1}^{n} \epsilon_{i}}{Q+\sum_{j=1}^{n} \epsilon_{j}}\right)^{2}$, where $\epsilon_{i}$ is firms production variation due to the introduction of the tax $\delta_{i}$. It is also easily verified that $q_{i}\left(\sigma_{i}\right)<q_{i}$ $\forall i$, therefore $\epsilon_{i}<0$. Therefore, $H I^{\prime}>H I$ is equivalent to $Q^{2}\left[2 \sum_{i=1}^{n} q_{i} \epsilon_{i}+\sum_{i=1}^{n} \epsilon_{i}^{2}\right]>$ $\sum_{i=1}^{n} \epsilon_{i} \sum_{i=1}^{n} q_{i}^{2}\left[2 Q+\sum_{i=1}^{n} \epsilon_{i}\right]$. As $\epsilon_{i}<0$, the latter expression holds if $Q^{2} \sum_{i=1}^{n} \epsilon_{i}^{2}>$ $\left(\sum_{i=1}^{n} \epsilon_{i}\right)^{2} \sum_{i=1}^{n} q_{i}^{2}$. This is true whenever $\left|\epsilon_{i}\right|<q_{i}$. Thus, the condition required ensures that the equilibrium after the firm-specific industrial policy is also interior $\left(q_{i}\left(\sigma_{i}\right)>0\right)$ $\forall i=1, \ldots, n$. 


\section{References}

-Bagwell, K and Staiger, R.W. (1994). "The Sensitivity of Strategic and Corrective R\&D Policy in Oligopolistic Industries." Journal of International Economics 36, 133-150.

-Barros, P. and Nilssen, T. (1999). "Industrial Policy and Firm Heterogeneity." Scandinavian Journal of Economics 101 (4), 597-616.

-Belleflamme, P. (2001). "Oligopolistic competition. IT use for product differentiation and the productivity paradox". International Journal of Industrial Organization 19 (1-2), $227-248$.

-Brander, J.A. and Spencer, B.J. (1983). "Strategic Commitment with R\&D: the symmetric case." Bell Journal of Economics 14, 225-235.

-Connolly, R. and Hirschey, M. (1984). "R\&D, market structure and profits: a valuebased approach". The Review of Economics and Statistics 66(4), 682-86.

-D' Aspremont, C. and Jacquemin, A.(1988). "Cooperative and noncooperative R\&D in a duopoly with spillovers". American Economic Review 78, 1133-1137.

-Kamien,-Morton-I; Schwartz,-Nancy-L. (1991). "Market Structure and Innovation: A Survey", Microeconomics: Theoretical and applied. Volume 2. International Library of Critical Writings in Economics, no. 11 Aldershot, U.K. and Brookfield, Vt.: Elgar 1991; 217-53.

-Miyagiwa, K. and Ohno, Y. (1997). "Strategic R\&D Policy and Appropiability". Journal of International Economics 42, 125-148.

-Nelson, R. and Winter. S. (1982). "The Schumpeterian Tradeoff Revisited". The American Economic Review 72 (1), 114-132.

-Poyago-Theotoky, J. (1996). "R\&D Competition with Asymmetric Firms". Scottish Journal of Political Economy 43, 334-342.

-Rosen, R.J. (1991), "Research and Development with Asymmetric Firm Sizes." RAND Journal of Economics 22, 411-429.

-Saloner, G. Shepard, A. (1995). "Adoption of Technologies with Network Effects: An Empirical Examination of the Adoption of Automated Teller Machines." RAND Journal of Economics 26(3), 479-501.

-Saracho, A. I. (2002). "Patent Licensing under Strategic Delegation". Journal of Economics and Management Strategy 11(2), 225-51. 
-Schumpeter, J. (1942). "Capitalism, Socialism, and Democracy". New York: Harper and Row, 1942.

-Spence, M. (1984). "Cost reduction, competition and industrial performance. Econometrica 52, 101-122.

-Spencer, B.J. and Brander, J.A. (1983). "International R\&D Rivalry and Industrial Strategy". Review of Economic Studies 50, 707-722.

-Xiangkang, Y. and Zuscovitch, E. (1998). "Is firm size conductive to R\&D choice? A strategic analysis of product and process innovations". Journal of Economic Behavior \& Organization Vol. 35, 243-262. 


\section{CFS Working Paper Series:}

\begin{tabular}{|c|c|c|}
\hline No. & Author(s) & Title \\
\hline $2003 / 41$ & $\begin{array}{l}\text { Sharon Kozicki } \\
\text { P.A. Tinsley }\end{array}$ & $\begin{array}{l}\text { Permanent and Transitory Policy Shocks in an } \\
\text { Empirical Macro Model with Asymmetric } \\
\text { Information }\end{array}$ \\
\hline $2003 / 42$ & $\begin{array}{l}\text { Mordecai Kurz } \\
\text { Hehui Jin } \\
\text { Maurizio Motolese }\end{array}$ & $\begin{array}{l}\text { The Role of Expectations in Economic } \\
\text { Fluctuations and the Efficacy of Monetary Policy }\end{array}$ \\
\hline $2003 / 43$ & $\begin{array}{l}\text { William A. Brock } \\
\text { Steven N. Durlauf } \\
\text { Kenneth D. West }\end{array}$ & $\begin{array}{l}\text { Policy Evaluation in Uncertain Economic } \\
\text { Environments }\end{array}$ \\
\hline $2003 / 44$ & $\begin{array}{l}\text { Timothy Cogley } \\
\text { Sergei Morozov } \\
\text { Thomas J. Sargent }\end{array}$ & $\begin{array}{l}\text { Bayesian Fan Charts for U.K. Inflation: } \\
\text { Forecasting and Sources of Uncertainty in an } \\
\text { Evolving Monetary System }\end{array}$ \\
\hline $2003 / 45$ & Guenter W. Beck & $\begin{array}{l}\text { Nominal Exchange Rate Regimes and Relative } \\
\text { Price Dispersion: On the Importance of Nominal } \\
\text { Exchange Rate Volatility for the Width of the } \\
\text { Border }\end{array}$ \\
\hline $2003 / 46$ & $\begin{array}{l}\text { Michael Ehrmann } \\
\text { Marcel Fratzscher }\end{array}$ & $\begin{array}{l}\text { Equal size, equal role? } \\
\text { Interest rate interdependence between the euro } \\
\text { area and the United States }\end{array}$ \\
\hline $2003 / 47$ & Romain Bouis & $\begin{array}{l}\text { IPOs Cycle and Investment in High-Tech } \\
\text { Industries }\end{array}$ \\
\hline
\end{tabular}

2003/48 Martin D. Dietz

Screening and Advising by a Venture Capitalist with a Time Constraint

Betting on Death and Capital Markets in Retirement: A Shortfall Risk Analysis of Life Annuities versus Phased Withdrawal Plans

Raimond Maurer

Olivia S. Mitchell

Are IPOs of Different VCs Different?

2004/02 Tereza Tykvová

Uwe Walz

2004/03 Marc Escrihuela-Villar

Innovation and Market Concentration with Asymmetric Firms

Copies of working papers can be downloaded at http://www.ifk-cfs.de 